\title{
COMPARATIVE STUDY OF CODES FOR SEISMIC DESIGN OF STRUCTURES
}

\begin{abstract}
SERGIO HAMPSHIRE DE C. SANTOS - Associated Professor, Federal University of Rio de Janeiro, Brazil, Rua Rainha Guilhermina 74/801, Rio de Janeiro, Brazil, e-mail: sergiohampshire@gmail.com

LUCA ZANAICA - Senior Structural Engineer, NET Engineering S.p.A, Monselice, Italy

CARMEN BUCUR - Professor, Technical University of Civil Engineering, Bucharest, Romania, e-mail: bucur_ig@utcb.ro

SILVIO DE SOUZA LIMA - Associated Professor, Federal University of Rio de Janeiro, Brazil

ANA ARAI - Graduated Student, Federal University of Rio de Janeiro, Brazil

Abstract: This paper presents a comparative evaluation among some international, European and American, seismic design standards. The study considers the criteria for the analysis of conventional (residential and commercial) buildings. The study is focused on some critical topics: definition of the recurrence periods for establishing the seismic input; definition of the seismic zonation and shape of the design response spectra; consideration of local soil conditions; definition of the seismic force-resisting systems and respective response modification coefficients; definition of the allowable procedures for the seismic analysis. A model for a standard reinforced concrete building ("Model Building") has been developed to permit the comparison among codes. This building has been modelled with two different computer programs, SAP2000 and SOFiSTiK and subjected to seismic input according to the several seismic codes. The obtained results compared are leading to some important conclusions.
\end{abstract}

Keywords: seismic analysis, seismic standards, comparative analysis, modelling.

\section{Introduction}

The Working Group 7 (WG7 - Earthquake Resistant Structures) of the International Association for Bridge and Structural Engineering (IABSE) has proposed, inside its Field of Activities and Objectives, studies of comparisons among seismic codes. Some of the members of WG7 have been assembled in a Subgroup (SG-B - Seismic Codes Comparisons), in order to work together on this subject, with a view to finding out discrepancies and similarities among the codes, as well as to identify and fulfil some grey areas of knowledge.

This paper is aligned with this objective of the WG7- SG-B, presenting a comparative evaluation among some international, European and American, seismic design standards. The study considers the criteria for the analysis of conventional (residential and commercial) buildings. Criteria for the design and detailing of reinforced concrete buildings will be analyzed by the authors in a future paper.

This study is focused in some critical topics: definition of the recurrence periods for establishing the seismic input; definition of the seismic zonation and shape of the design response spectra; consideration of local soil conditions; definition of the seismic force-resisting systems and respective response modification coefficients and definition of the allowable procedures for the seismic analyses.

A standard reinforced concrete building ("Model Building") has been selected for the comparative analysis among codes. This building has been modelled with two different computer programs, SAP2000 and SOFiSTiK. The two models have been subjected to seismic input according to several codes mentioned above, and the results obtained have been compared. 


\section{Analyzed Standards}

The standards for seismic design of building structures listed below are considered in the comparative analysis:

- American Standard - ASCE/SEI 7-10 [1].

- Eurocode 8 - EN 1998-1:2004 [2].

- Italian Code - Technical Standard for the Constructions [3] and [4].

- Romanian Code and Romanian National Annex to Eurocode 8 [5] and [6].

- Brazilian Standard - NBR 15421:2006 [7].

Some details concerning the application of these standards are discussed further on.

\section{Comparative Analysis}

\subsection{Definition of Recurrence Periods for Definition of Seismic Input (Figure 1)}

Very different criteria have been found in the several codes for defining the recurrence periods. Eurocode 8 recommends, for the no-collapse requirement of a structure, the consideration of a recurrence period of 475 years. This corresponds to a probability of $10 \%$ of the seismic input being exceeded in 50 years.

The Brazilian Standard follows the same definition of Eurocode 8. The design ground accelerations for the design vary between $0.025 \mathrm{~g}$ and $0.15 \mathrm{~g}$ in the Brazilian territory, as shown in Fig 1a.

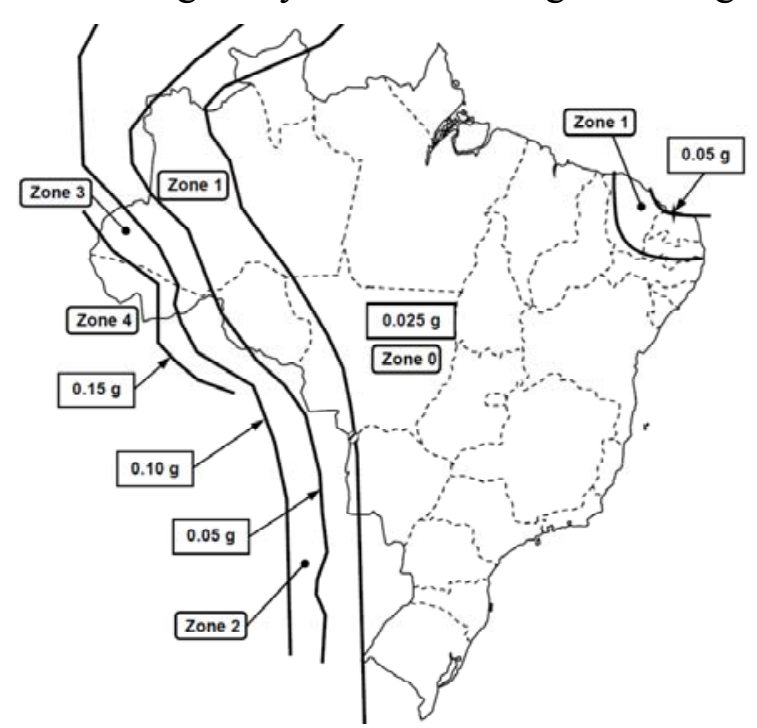

a. Seismic zonation of Brazil [7]

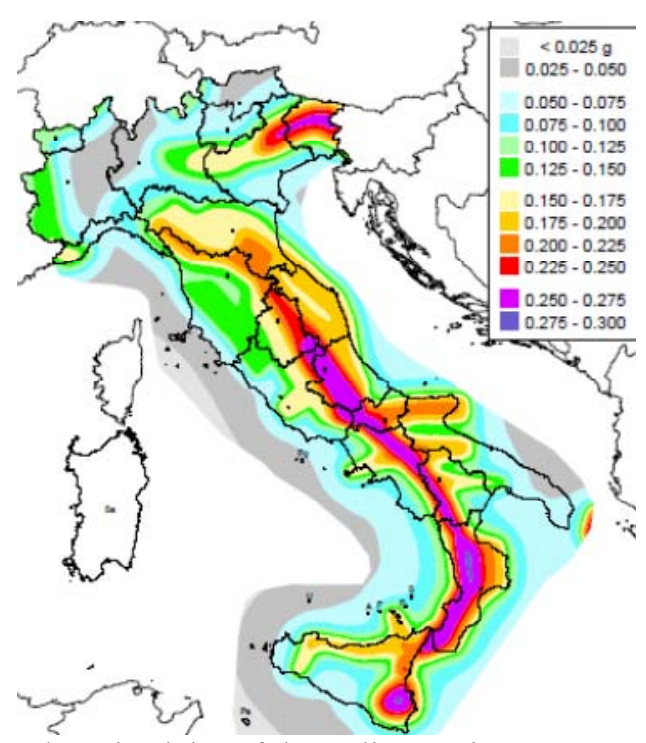

b. Seismicity of the Italian territory [11]

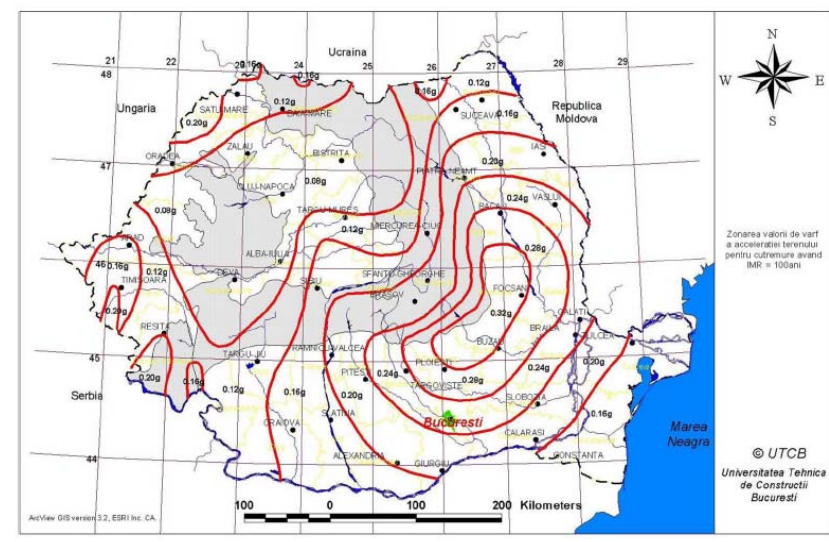

c. Seismicity of the Romanian territory [5]

Fig. 1 - The design ground accelerations 
The Italian code, focusing onto the building types which have been analysed into this paper, defines two seismic levels for the design of conventional buildings: a Damage Limit State level using an elastic spectrum with a recurrence period of 50 years (mainly for checking the maximum displacements and non-structural damage) and a Life Preservation Limit State level using a design spectrum with a recurrence period of 475 years (mainly for checking the structural resistance, ductility and stability). The design ground accelerations for the design vary between $0.025 \mathrm{~g}$ and $0.30 \mathrm{~g}$ in the Italian territory, as shown in Fig $1 \mathrm{~b}$.

The Romanian code defines a MRI (Mean Recurrence Interval) of 100 years for defining the design ground accelerations for the design. This value varies between $0.08 \mathrm{~g}$ and $0.32 \mathrm{~g}$ in the Romanian territory, as shown in Fig 1c.

The American standard ASCE/SEI 7/10 defines a recurrence period of 2475 years, which corresponds to a probability of $2 \%$ of the seismic input being exceeded in 50 years; nevertheless, economic reasons lead this standard to allow for a reduction factor of $2 / 3$ to be applied in the resulting values of the seismic design forces. The design ground accelerations for the design vary between $0.024 \mathrm{~g}$ and $0.80 \mathrm{~g}$ in the American territory.

\subsection{Definition of Seismic Zonation and Seismic Ground Motion Values}

Eurocode 8 transfers the responsibility for defining the seismic zonation for each of the National Authorities. In this standard, a single parameter defines the local seismicity: the ZPA ("Zero Period Acceleration") value of the reference peak ground acceleration in rock ground $\left(\mathrm{a}_{\mathrm{g}}\right)$. The same definition by a single parameter is also found in the Italian, Romanian and Brazilian codes. In the standard ASCE/SEI 7/10, the seismic input is defined through three basic parameters, i.e., the peak ground accelerations for the spectral periods of $0.2 \mathrm{~s}$ and $1.0 \mathrm{~s}$ and the period $\mathrm{T}_{\mathrm{D}}$ that defines the displacement governed region of the spectrum. These parameters are defined in the standard through very detailed maps.

\subsection{Shape Definition of Horizontal Elastic Response Spectra}

In order to make possible the comparison among the horizontal elastic response spectra defined in the several standards, Fig. 2 below reproduces Fig. 3.1 of Eurocode 8, that establishes the shape of its elastic response spectrum, including the several parameters that define it.

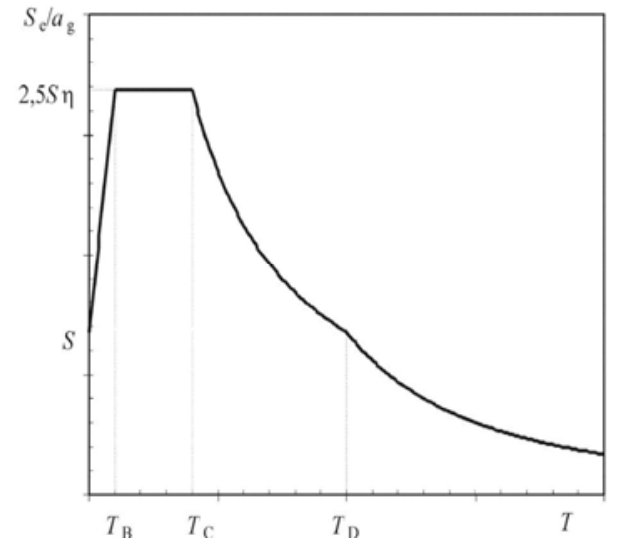

Fig.2 - Shape of the elastic response spectrum
In Eurocode 8 elastic response spectra, as well as in the elastic spectra of all the other analyzed standards, the pseudo-accelerations $\left(\mathrm{S}_{\mathrm{e}}\right)$ are given as a function of the structural periods $(\mathrm{T})$. The spectra vary proportionally to the peak ground acceleration $\left(\mathrm{a}_{\mathrm{g}}\right)$, times a soil coefficient $\mathrm{S}$, related to the soil amplification and considering the parameter $\eta$, the correction factor for damping values different from 5\%. All other analyzed standards consider, for the definition of the spectra, the nominal structural damping of $5 \%$.

The region between the reference periods $T_{B}$ and $T_{C}$ is the one acceleration controlled (constant acceleration); the region between periods $\mathrm{T}_{\mathrm{C}}$ and $\mathrm{T}_{\mathrm{D}}$ is the one velocity controlled (accelerations varying with the inverse of $T$ ); the region for periods superior to $T_{D}$ is the one displacement governed (accelerations varying with the inverse of $\mathrm{T}^{2}$ ). The region between 0 ( $\mathrm{ZPA}-$ "zero 
period acceleration") and $T_{B}$ is the transition region between the peak ground acceleration and the maximum spectral accelerations. The values of $S, T_{B}, T_{C}$ and $T_{D}$ are defined as a function of the type of subsoil in the two spectral types defined in the code, Types 1 or 2, related respectively to higher and lower seismicity regions, respectively.

The relationship $\beta$ between the maximum acceleration in the structure and the maximum ground acceleration is taken as 2.5 in Eurocode 8, the Brazilian Standard and ASCE/SEI 7/10. In the Romanian code, it is defined generally as 2.75 and as 3.0 only in the region of Banat. The value of $T_{C}$ is defined in a map in the Romanian code and $T_{B}$ and $T_{D}$ are defined in a table, as a function of $\mathrm{T}_{\mathrm{C}}$.

The specific values the peak ground accelerations $\left(a_{g}\right)$, and the above defined parameters $\beta$ and $\mathrm{T}_{\mathrm{C}}$ are defined in the Italian code through its Annex A.

The ASCE/SEI 7/10 defines this region showing the period $\mathrm{T}_{\mathrm{D}}$ through maps.

\subsection{Consideration of Specific Soil Conditions}

All the analyzed standards classify the ground conditions according to the shear wave propagation velocities $\left(\mathrm{v}_{\mathrm{s}}\right)$ and/or to the number of blows in the Standard Penetration Test $\left(\mathrm{N}_{\mathrm{SPT}}\right)$. For non-homogeneous sites, the criteria for averaging these parameters in the more superficial subsoil layers (typically in the first $30 \mathrm{~m}$ ) are proposed in the standards. The soil classes, varying from very stiff to soft deposits, are in Eurocode 8 classes $A$ to $E, S_{1}$ and $S_{2}$; in ASCE/SEI 7/10 and in Brazilian Standard, they vary between A to F; in the Italian code the soil classes are between $\mathrm{A}$ to $\mathrm{E}, \mathrm{S}_{1}$ and $\mathrm{S}_{2}$. In the Romanian code, the specific soil conditions are considered only in the definition of parameter $\mathrm{T}_{\mathrm{C}}$, which expresses the frequency content related to each of the soil classes. For design, the local site conditions are classified in three zones, $Z_{1}$, $\mathrm{Z}_{2}, \mathrm{Z}_{3}$ defined in a map and reproduced in Fig. 3. The Brazilian and Italian Codes do not have a soil zonation map. A common definition in these codes is that soil tests have to be made in each particular site.

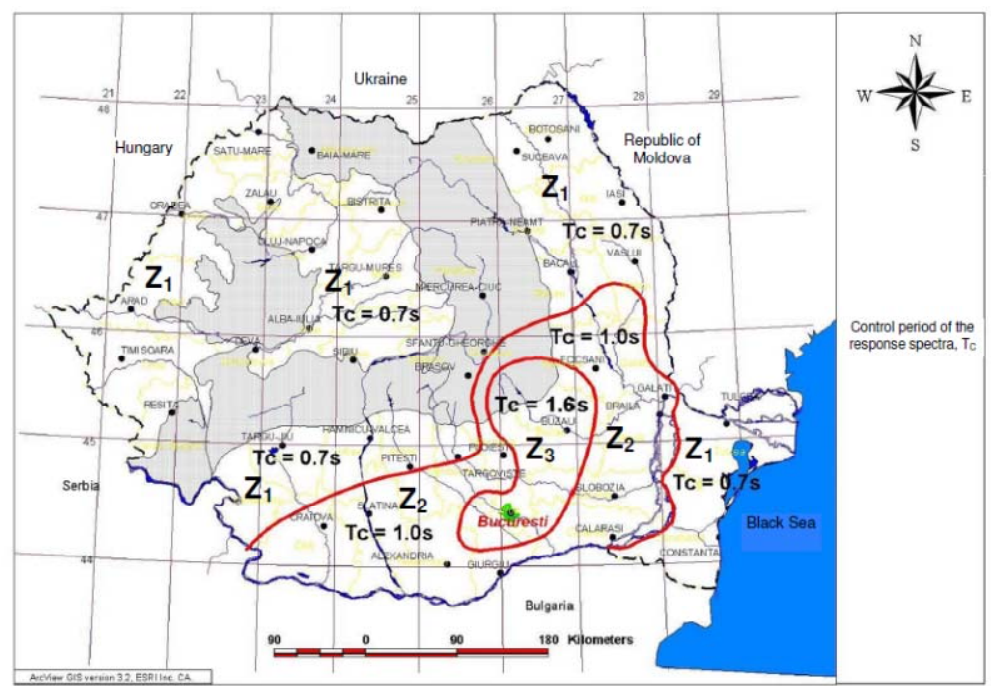

Fig. 3 - Soil conditions - Zonation of the Romanian territory in terms of control period $\mathrm{T}_{\mathrm{C}}$ of the response spectrum

The seismic soil amplification in more or less stiff layers influences the definition of the shape of the response spectra; in less stiff deposits, the soil amplification is higher, leading to greater values of the soil coefficients $\mathrm{S}$.

All the analyzed standards define a separate class for liquefiable soils (e.g., Class $\mathrm{S}_{2}$ in the Eurocode 8). Soil-structure interaction is only considered in ASCE/SEI 7/10 (Chapter 19). 


\subsection{Classification of Structures in Different Importance Levels}

All the analyzed standards recognize the necessity of classifying the structures in Importance Classes. This implies in a reliability differentiation, according to the estimated risk and/or consequences of a failure. This reliability differentiation is simply defined in the standards by the application of a multiplying factor I to the evaluated seismic forces. Three or four Importance Classes are defined in the standards. In all of them, the factor $\mathrm{I}=1$ is assigned to usual structures, such as residential and commercial buildings.

The Risk Categories are I to IV in the ASCE/SEI 7/10, with the factor I varying between I $=1.0$ to $\mathrm{I}=1.5$. Three Importance Classes are defined in the Brazilian Standard, with the same variation of the parameter I. Four Importance Classes are defined in Eurocode 8 and also in the Romanian code, with the factor I varying in both standards between $\mathrm{I}=0.8$ and $\mathrm{I}=1.4$. In the Italian code, the reliability differentiation is directly applied in the definition of different return periods and the respective limit states for the design of structures, divided in four different "Use Classes".

\subsection{Seismic Force-resisting Systems and Subsequent Response Modification Coefficients}

All the analyzed standards recognize the impossibility of requiring that the structures behave in a purely elastic way. Under seismic excitation, the structures are expected to behave in the non-linear range, developing large deformations and dissipating a large amount of energy. For this, the structures should be designed and detailed in order to ensure the necessary capacity of energy dissipation. As long as the necessary degree of ductility is ensured, it is possible to consider the transformation of the elastic spectra in design spectra, in which the considered ductility is implied.

All standards define the reduction factors as a function of the structural systems and of the structural materials. The reduction factors ("R" in ASCE/SEI 7/10 and Brazilian code or "q" in Eurocode, Italian and Romanian code) are also expressed as a function of the ductility classes (e.g., medium and high ductility in the Eurocode 8 or ordinary, intermediate and special detailing in the ASCE/SEI 7/10). The numerical value of these coefficients is often empirically defined in the standards according to past experience and/or good engineering judgement. A comprehensive analysis of these coefficients is outside the scope of this paper.

\subsection{Structural Irregularities and Allowed Procedures for Seismic Analysis}

All the analyzed standards are strict in recommending, as stated in item 4.2.1 of Eurocode 8, the following basic principles in the conceptual design of a construction: structural simplicity, uniformity and regularity in plan and in elevation, bi-directional and torsional resistance and stiffness, diaphragmatic behaviour in the floor plans and adequate foundation.

Irregularity in plan or elevation are punished by the standards, that require accordingly more elaborated methods of analysis, more stringent criteria for the consideration of design forces, etc.

For regular and simple structures, all the standards allow for a lateral force (static equivalent) method of analysis, when the contribution of the fundamental mode in each horizontal direction is preponderant in the dynamic response. All the standards provide also formulas for the approximate evaluation of the fundamental periods of a structure. The use of two planar models, one for each horizontal direction, is typically allowed only for regular structures.

All the standards allow also the use of the modal response spectrum analysis. In all the analyzed standards, the required number of considered modes ensure that at least $90 \%$ (85\% for the Italian standard) of the total mass of the structure should be captured in each orthogonal horizontal direction. For the combination of the modal components, the Complete Quadratic Combination (CQC) rule is considered as the preferable one in almost all standards. ASCE/SEI 7/10 indicates 
a limitation in the structural periods obtained analytically, by comparing them with periods obtained with approximate empirical evaluation formulas.

The standards also allow the linear time-history analysis, using recorded or artificial time-histories matching the design response spectra, applied simultaneously at least in the two horizontal directions. ASCE/SEI 7/10 and the Brazilian standards require the comparison between the results obtained with the time history analysis with the ones obtained with a spectral analysis.

Some codes (e.g. Eurocode 8) admit the non-linear analysis in the time domain, but as long as they are substantiated with respect to more conventional methods. Some codes (e.g. Eurocode 8) allow also for non-linear static (pushover) analyses.

\section{Numerical Example}

\section{1 Considered Building Data}

A simple and symmetrical building structure (the "Model Building") has been chosen as an example for illustrating the comparison among the seismic standards. This model is an adaptation of the one already analyzed by Gosh and Fanella [10]. The main data of the building are:

- Nominal concrete strength: fck $=28 \mathrm{MPa}$.

- Young modulus of concrete: $\mathrm{Ec}=32 \mathrm{GPa}$.

- Concrete specific weight: $\gamma \mathrm{c}=25 \mathrm{kN} / \mathrm{m}^{3}$.

- Non-structural finishing weight, typical floors: $1.5 \mathrm{kN} / \mathrm{m} 2$.

- Non-structural finishing weight, top floor: $0.5 \mathrm{kN} / \mathrm{m} 2$ (distributed) plus four concentrated loads of $900 \mathrm{kN}$.

- Plan dimensions: $20.1 \mathrm{~m}$ x $55.3 \mathrm{~m}$ (between axes of columns).

- Total building height: $45.15 \mathrm{~m}$, in 12 floors

- Dimensions of the exterior columns: $60 \mathrm{~cm}$ x $60 \mathrm{~cm}$

- Dimensions of the interior columns: $65 \mathrm{~cm}$ x $65 \mathrm{~cm}$

- Dimensions of the beams: $55 \mathrm{~cm} \mathrm{x} 90 \mathrm{~cm}$

- Thickness of the slabs: $20 \mathrm{~cm}$

- Thickness of the two shear-walls: $30 \mathrm{~cm}$

- Total weight of the building: $154143 \mathrm{kN}$

Formwork drawings and a longitudinal section of the Model Building are presented in Figure 4. Schematic perspectives of the building, drawn by programs SOFiSTiK and SAP2000 are shown in Figure 5.

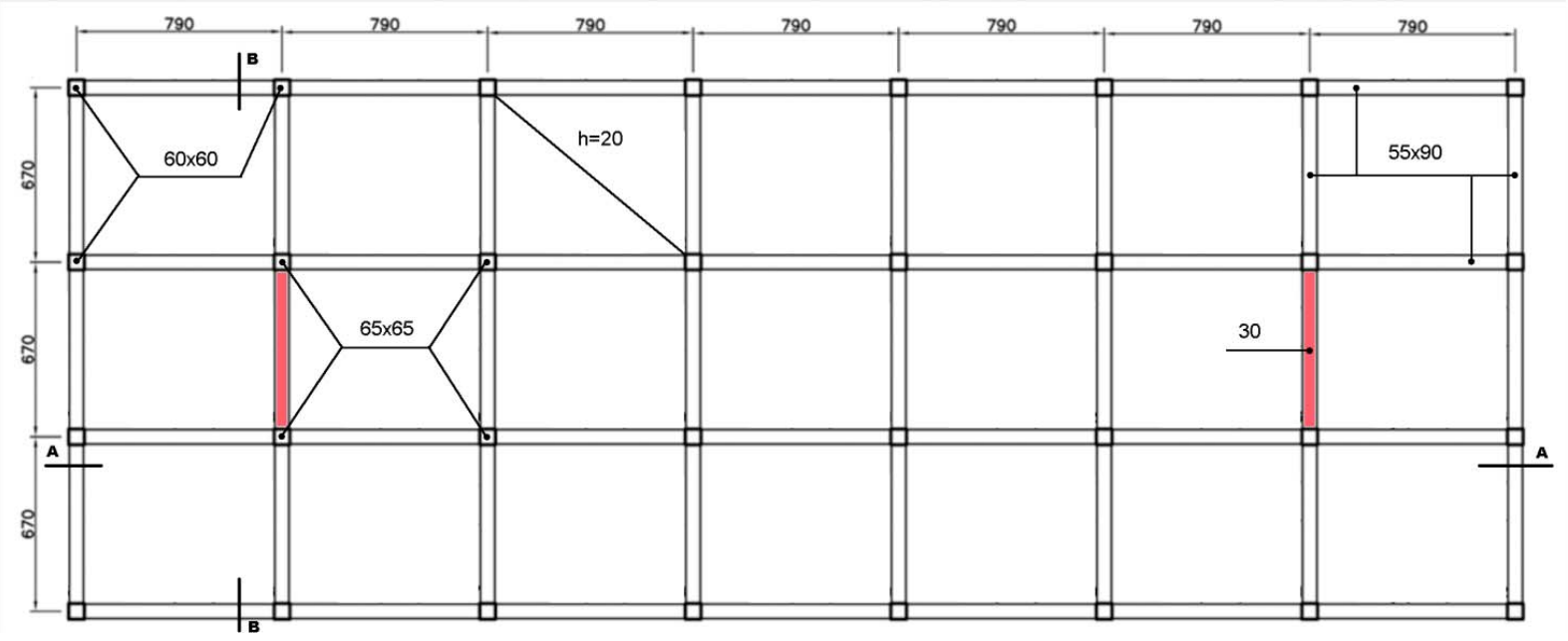

a. Typical floor plan 


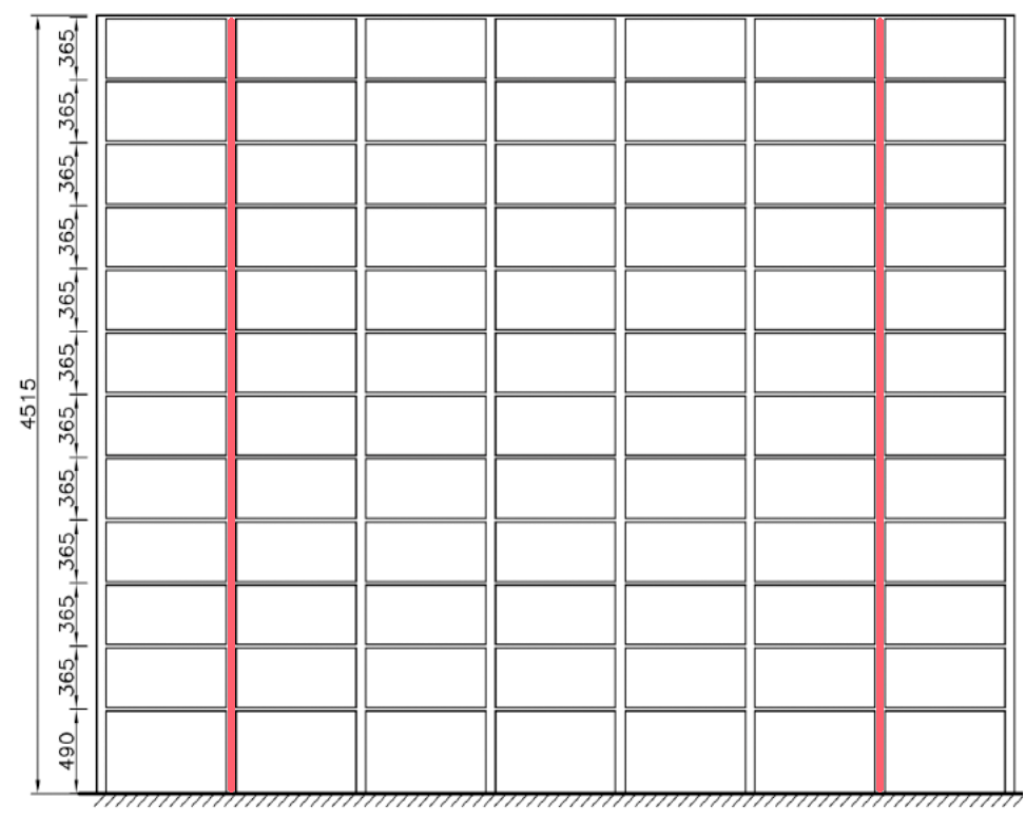

b. Longitudinal section (A-A)

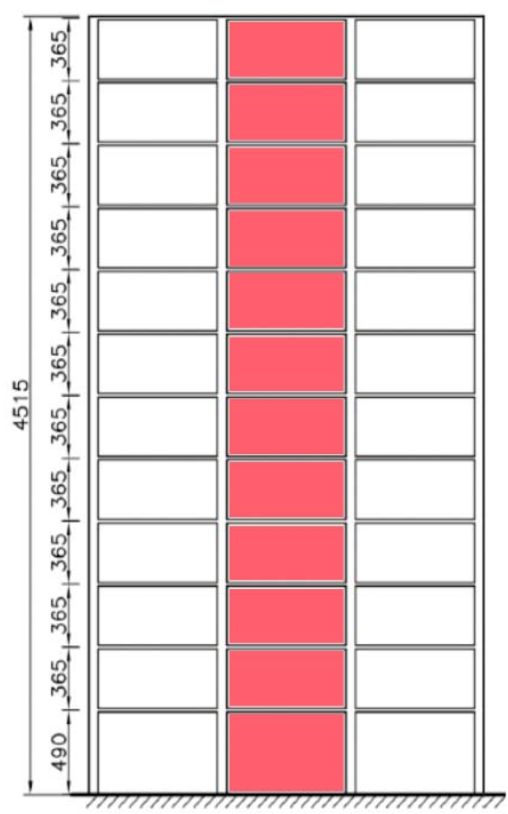

c. Transversal section (B-B)

Fig. 4 - Model Building

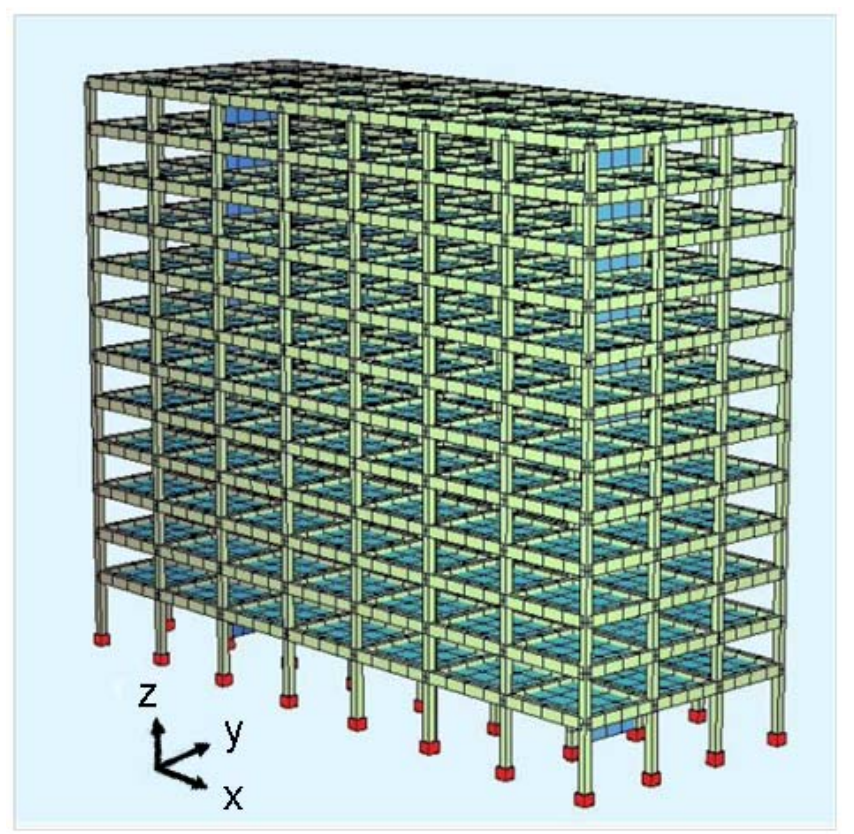

a. Perspective generated by SOFiSTiK

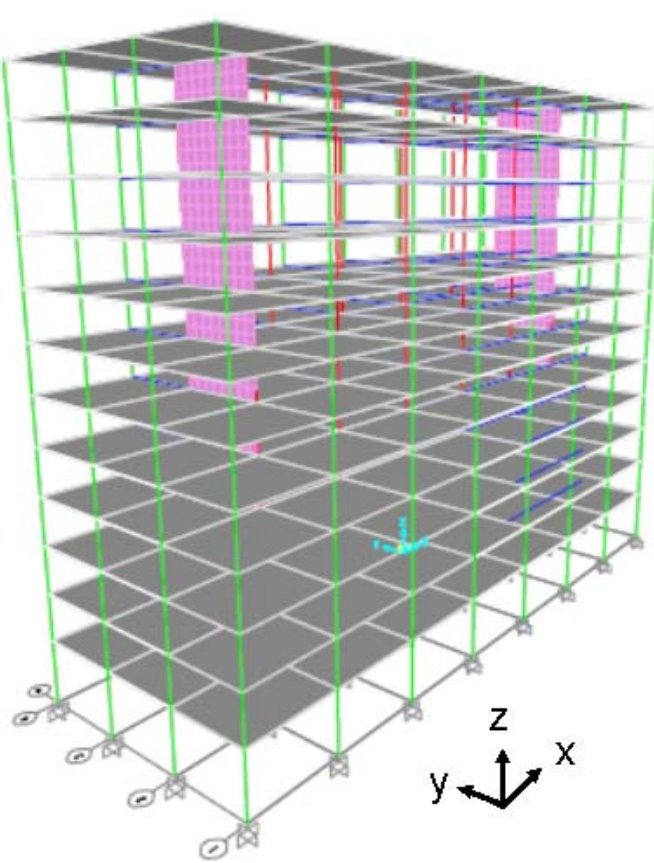

b. Perspective generated by SAP 2000

Fig. 5 - Model Building

\subsection{Considered Seismic Data}

In order to make possible the comparison among the several standards, a particular location has been carefully chosen. It is supposed that the building is located in Reevesville, South Carolina (ZIP code 29471), U.S. Considering a 475 years return period, the design ground acceleration, for rock conditions, in this location can be taken as $a_{g}=0.15 \mathrm{~g}$. This relatively small level of seismicity has been chosen is order to make possible the comparison among all the analyzed 
standards, since this is the highest level of seismicity considered in the Brazilian Standard. Figure 6 shows the elastic spectra obtained according the several standards.

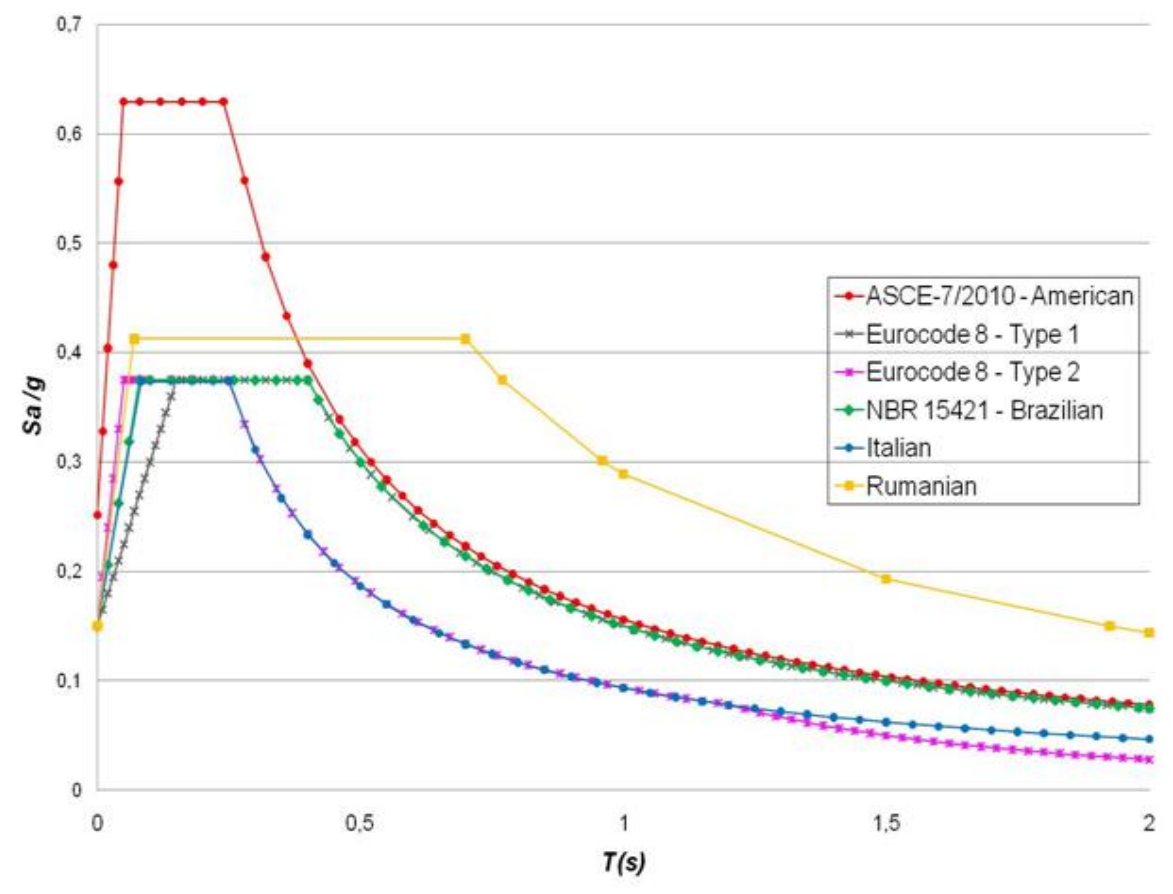

Notice: The ASCE/SEI 7/2010 considers the recurrence period of 2475 years,

Fig.6 - Elastic response spectra according to several standards

The two types of spectra defined by Eurocode 8 are presented, Type 1, applicable to regions of higher seismicity and Type 2, adequate for regions of smaller seismicity. In the Type 2 spectrum, the higher accelerations are concentrated in the $0.1 \mathrm{~s}-0.25 \mathrm{~s}$ periods range; as a result, in the range of the fundamental periods of the analyzed structure, the Type 2 accelerations given by Eurocode 8 are much smaller than the ones given by the other codes. The Italian code spectrum follows the same trend of Eurocode Type 2 spectrum.

It is to be noticed that all the presented spectra consider the same seismicity $\left(a_{g}=0.15 \mathrm{~g}\right)$ and the same type of soil (rock ground). It is also to be noticed that, as long as only the ASCE/SEI 7/10 considers the recurrence period of 2475 years, its design spectrum presents numerical values superior to the ones corresponding to the other codes.

\subsection{Analysis Results}

In order to make possible a direct comparison among the standards, the analyses have been done using the elastic spectra, without the consideration of the response modification factors (reduction factors due to the non-linear behaviour).

The spectral analyses of the building have been performed using the computer programs SAP2000 [8] and SOFiSTiK [9], for the six defined spectra, Fig. 6. The periods and the Modal Participation Mass Ratios obtained as results of the modal extraction performed by the programs SOFiSTiK and SAP2000 are shown in Table 1. Very similar results have been found with the two programs. For this, the further presented results are the ones obtained with the model studied with the SAP2000 program.

The first mode with $\mathrm{T}_{1}=1.51 \mathrm{~s}$ defines the structure as flexible. The vibration shape is typical for bending, parallel to the long side of the building. Figure 7 shows the graphical representation of the first mode shapes, extracted by SOFiSTiK and SAP2000. The second mode $\left(\mathrm{T}_{2}=1.08 \mathrm{~s}\right)$ appears in the transversal direction (Y). 
Periods and Modal Participation Mass Ratios

\begin{tabular}{|c|l|c|c|c|c|c|}
\hline \multirow{2}{*}{ Mode } & \multirow{2}{*}{ Direction of vibration } & SOFiSTiK & \multicolumn{4}{|c|}{ Seriod } \\
\cline { 4 - 7 } & & & & \multicolumn{3}{|c|}{ Modal Participation Mass } \\
\cline { 5 - 7 } & & $\begin{array}{c}\text { Period } \\
{[\mathrm{sec}]}\end{array}$ & $\begin{array}{c}\text { longitudinal } \\
\%\end{array}$ & $\begin{array}{c}\text { transversal } \\
\%\end{array}$ & $\begin{array}{c}\text { vertical } \\
\%\end{array}$ \\
\hline 1 & $1 / 4$ wave longitudinal & 1.45815 & 1.5142 & 0.86214 & 0 & 0 \\
\hline 2 & $1 / 4$ wave transversal & 1.06067 & 1.07771 & 0.86214 & 0.7401 & $2 \mathrm{E}-18$ \\
\hline 3 & torsion & 0.93264 & 0.93766 & 0.86214 & 0.7401 & $4.1 \mathrm{E}-18$ \\
\hline 4 & $3 / 4$ wave longitudinal & 0.48222 & 0.49877 & 0.95355 & 0.7401 & $1.3 \mathrm{E}-17$ \\
\hline 5 & $3 / 4$ wave transversal & 0.29987 & 0.29882 & 0.95355 & 0.89957 & $5 \mathrm{E}-16$ \\
\hline 6 & $5 / 4$ wave longitudinal & 0.28136 & 0.28973 & 0.97921 & 0.89957 & $8 \mathrm{E}-16$ \\
\hline 7 & $\begin{array}{l}\text { longitudinal + transversal } \\
\text { coupling }\end{array}$ & 0.26554 & 0.26476 & 0.97921 & 0.89957 & $1.3 \mathrm{E}-15$ \\
\hline 8 & $7 / 4$ wave longitudinal & 0.19697 & 0.20231 & 0.98923 & 0.89957 & $5.7 \mathrm{E}-15$ \\
\hline 9 & $2 / 4$ wave vertical, central & 0.17952 & 0.19205 & 0.98923 & 0.89957 & 0.47732 \\
\hline 10 & $4 / 4$ wave vertical & 0.15563 & 0.16242 & 0.98923 & 0.89957 & 0.47732 \\
\hline 11 & $9 / 4$ wave longitudinal & 0.15034 & 0.15431 & 0.9937 & 0.89957 & 0.47732 \\
\hline 12 & $\begin{array}{l}\text { transversal + vertical } \\
\text { coupling }\end{array}$ & 0.14987 & 0.15355 & 0.9937 & 0.9076 & 0.47732 \\
\hline 13 & $\begin{array}{l}\text { transversal + vertical } \\
\text { coupling }\end{array}$ & 0.14355 & 0.14668 & 0.9937 & 0.95412 & 0.47732 \\
\hline
\end{tabular}

The $3^{\text {rd }}$ mode is torsional and the $9^{\text {th }}$ mode is vertical. Up to the $5^{\text {th }}$ mode, $90 \%$ of the total mass is captured in both horizontal directions. Figure 8 shows the graphical representation of the second, third and ninth mode shapes, extracted by SAP2000.

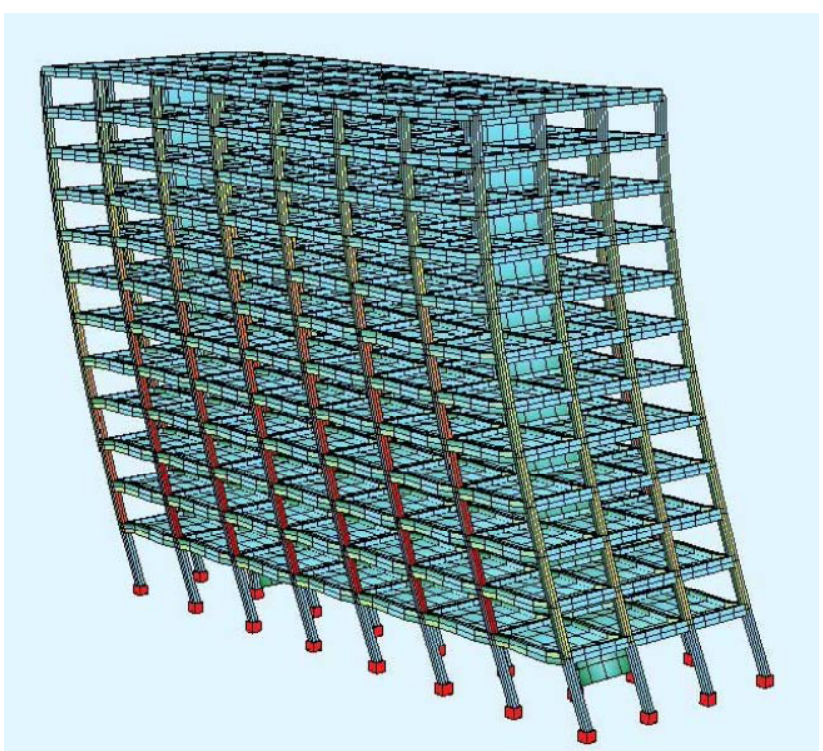

a. First mode shape obtained with SOFiSTiK

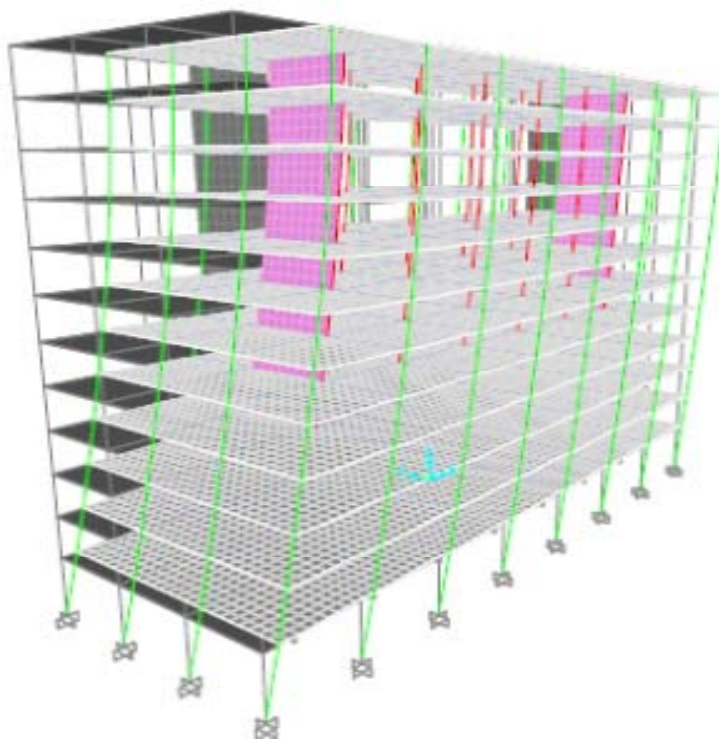

b. First mode shape obtained with SAP2000

Fig. 7 - Model Building - Fundamental mode 


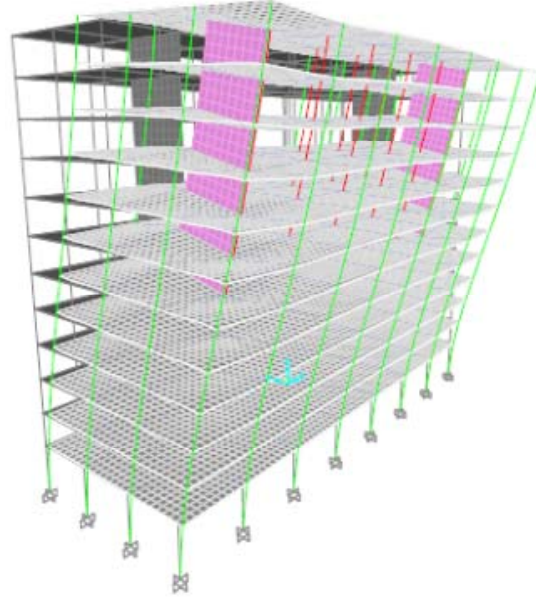

a. Second mode - transversal vibration

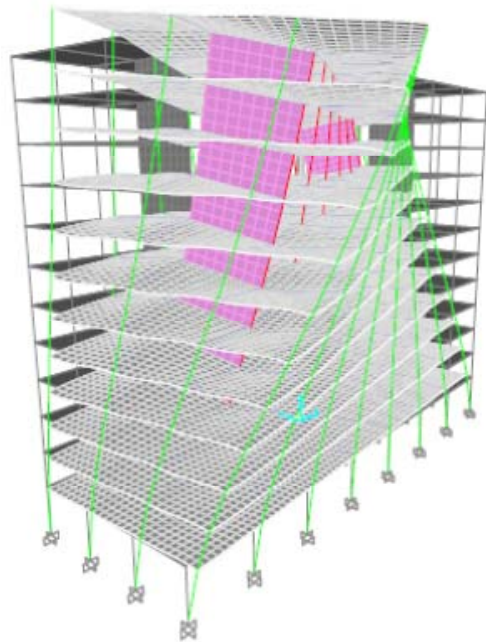

b. $3^{\text {rd }}$ mode - torsion

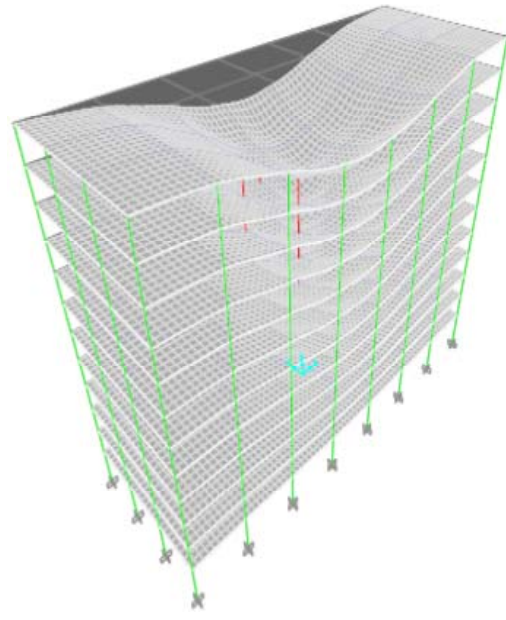

c. $9^{\text {th }}$ mode - vertical vibration

Fig. 8 - Model Building - Modes

The displacements obtained in the top part of the building are presented in Fig. 9 and 10 for longitudinal (X) and respectively transversal (Y), directions. These displacements are obtained in spectral analyses using the CQC rule for the combination of the modal components.

As already commented, due to the consideration in the Eurocode 8, of the Type 2 spectrum and also of the spectrum of the Italian code, the displacements and forces obtained with these codes are dramatically inferior to the ones obtained with the other codes.

The total horizontal forces at the basis of the building by spectral analyses are shown in Fig. 11 and 12. The figures also show the total horizontal forces obtained through the static equivalent procedures defined in the standards (in the legend, "Codes").

In all the analyzed standards, the total horizontal forces obtained with the static equivalent methods are always conservative when compared with the ones obtained in the spectral analyses.

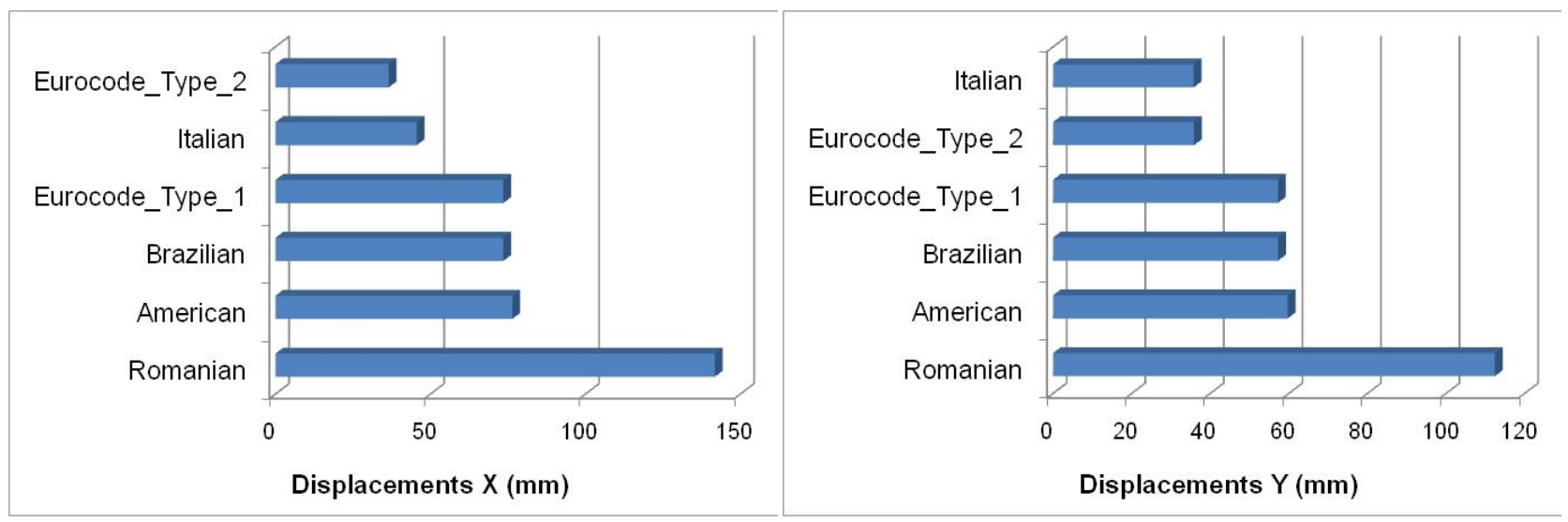

Fig.9 - Obtained displacements, longitudinal direction (X)

Fig.10 - Obtained displacements, transversal direction (Y) 


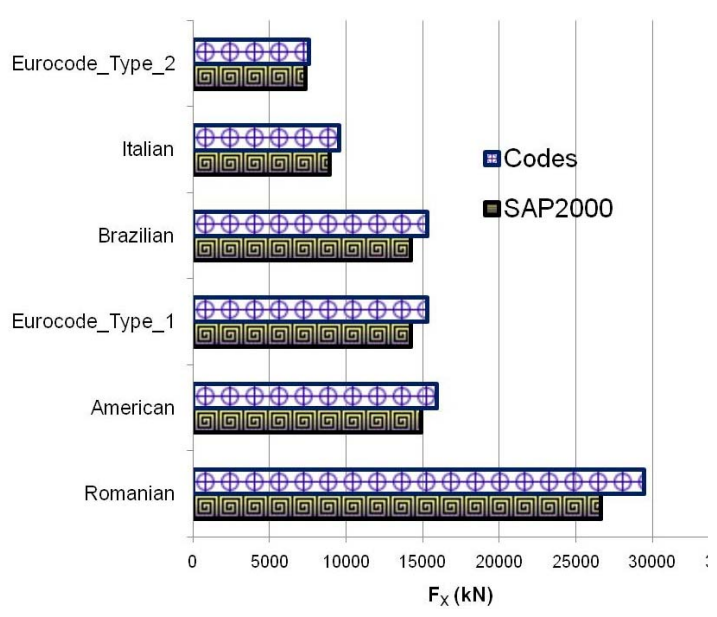

Fig.11 - Obtained total forces, longitudinal direction (X)

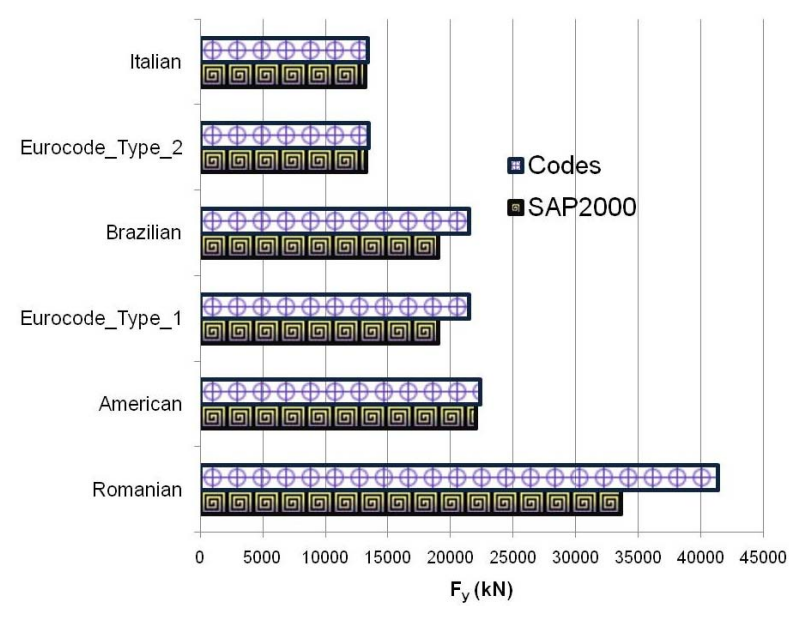

Fig.12 - Obtained total forces, transversal direction (Y)

\section{Conclusions}

The comparison of the text of the several analyzed seismic standards indicates a general agreement regarding the desired main characteristics of a seismic resistant structure: simplicity, symmetry, uniformity, redundancies, etc. An essential point generally focused as well is the necessity that the structural design and detailing should provide enough ductility for the dissipation of energy in the non-linear range.

On the other hand, the differences in the shapes of the design spectra lead to differences in the results, in some cases, superior to $100 \%$. Obviously, this is a point to be better analyzed other comparative studies in the future.

Another point, already stressed, that should be further investigated, regards the definition of the spectral shape. Except the ASCE/SEI 7/10, the shapes of the spectra are governed by a single parameter, the peak ground acceleration. Eurocode 8 defines two different spectral types, associated with the magnitude that prevails in the seismic risk of the analyzed site. In the ASCE/SEI 7/10, the spectral shape is defined with three basic parameters, i.e., the peak ground accelerations for the spectral periods of $0.2 \mathrm{~s}$ and $1.0 \mathrm{~s}$ and the period $\mathrm{T}_{\mathrm{D}}$ that defines the displacement governed region of the spectrum.

Another very important issue to be discussed in the future regards the definition of the recurrence periods. The ASCE/SEI 7/10 already redefined this parameter from the traditional 475 years to 2475 years. Adopting this definition would lead, as a major consequence, to an important increase in the design seismic forces presently defined in the standards. This discussion is essential and urgent.

As shown in this paper, there are some important issues that shall be discussed in the future in the engineering community, envisaging future revisions in the seismic standards. It is expected that this paper could be of some value for encouraging the future improvement of these seismic standards.

\section{References}

[1] American Society of Civil Engineers (ASCE) (2010). Minimum Design Loads for Buildings and Other Structures (ASCE/SEI 7-10), American Society of Civil Engineers, Washington, D.C.

[2] European Committee for Standardization. (2004). Eurocode 8: Design of Structures for Earthquake Resistance Part 1: General Rules, Seismic Actions and Rules for Buildings. EN 1998-1:2004 ECS, Brussels.

[3] Italian Ministry of Infrastructures.(2008). Italian Ministerial Decree of 14/01/08: Norme Tecniche per le Costruzioni (Technical Standard for the Constructions. 
[4] Italian Ministry of Infrastructures. (2009). Italian Circular No. 617 of 02/02/09: Istruzione per l'Applicazione delle "Norme Tecniche per le Costruzioni (Instructions for the Application of the "Technical Standard for the Constructions).

[5] Romanian Ministry of Transports, Construction and Tourism. (2007). Seismic Design Code, Part 1 - P100-1/2006, Earthquake Resistant Design of Buildings.

[6] Romanian Standards Association. (2008). Eurocode 8: Design of Structures for Earthquake Resistance - Part 1: General Rules, Seismic Actions and Rules for Buildings. National Annex SR EN 1998-1

[7] Associação Brasileira de Normas Técnicas. (2006). Projeto de Estruturas Resistentes a Sismos (Design of Seismic Resistant Structures) NBR 15421. ABNT, Rio de Janeiro, Brazil, (in Portuguese).

[8] CSI Computers \& Structures, Inc. (2010). SAP2000, Integrated Software for Structural Analysis \& Design, Version 14. CSI Inc, Berkeley, California, USA.

[9] SOFiSTiK A.G. SOFiSTiK - Finite Element Software, from: www.sofistik.com

[10] Gosh, SK., Fanella, DA. (2003). Seismic and Wind Design of Concrete Buildings. International Code Council, Falls Church, VA, USA.

[11] Istituto Nazionale di Geofisica e Vulvanologia. Mappa di pericolosità sismica del territorio nazionale, from: http://zonesismiche.mi.ingv.it/documenti/mappa_opcm3519.pdf 